\title{
High Proportion of Pituitary Abnormalities and Other Congenital Defects in Children with Congenital Nasal Pyriform Aperture Stenosis
}

\author{
SOPHIE GUILMIN-CRÉPON, CATHERINE GAREL, CLARISSE BAUMANN, DOMINIQUE BRÉMOND-GIGNAC, \\ ISABELLE BAILLEUL-FORESTIER, SUZEL MAGNIER, MIREILLE CASTANET, PAUL CZERNICHOW, \\ THIERRY VAN DEN ABBEELE, AND JULIANE LÉGER
}

Pediatric Endocrinology and Diabetes Unit, Centre de Référence Maladies Endocriniennes Rares de la Croissance [S.G.-C., M.C., P.C., J.L.], Radiology [C.G.], Clinical Genetic [C.B.], Ophthalmology [D.B.-G.], Stomatology [I.B.-F.], Cardiology [S.M.], Otorhinolaryngology Departments [T.A.], Hôpital Robert Debré, Assistance Publique-Hôpitaux de Paris, Paris VII University;

75019 Paris, France

\begin{abstract}
We aimed to determine the occurrence of pituitary dysfunction and additional malformations in patients with congenital nasal pyriform aperture stenosis (CNPAS) and to predict which patients are at risk of pituitary dysfunction. Among the 40 studied patients, hypothalamo-pituitary (HP) axis abnormalities were found in 16 patients $(40 \%)$, with endocrine dysfunction $(n=9)$ and/or abnormal HP MRI findings $(n=15)$. A normal HP axis on MRI was highly predictive of normal endocrine function. Of the 40 patients, 31 had additional abnormalities in the cranio-facial area $(n=26)$, the brain $(n=12)$, the vertebrae $(n=5)$, the limbs $(n=4)$, the heart $(n$ $=7)$ and the kidney $(n=3)$. Six patients had syndromic associations: VACTERL $(n=4)$, CHARGE $(n=1)$ and RHYNS $(n=1)$ syndromes. Craniofacial and brain malformations were more common in patients with HP axis abnormalities than in patients with normal HP axis. Familial history of midline defects and/or consanguinity were found in $30 \%$ of patients.

In conclusion, HP axis abnormalities are frequent in patients with CNPAS and justify MRI of the brain early in life and clinical evaluation to screen for patients with pituitary insufficiency. CNPAS may be a genetically heterogeneous condition with a large phenotypic variability that shares common etiological mechanisms with the various forms of the holoprosencephaly phenotype. (Pediatr Res 60: 478-484, 2006)
\end{abstract}

$\mathrm{C}$ ongenital nasal pyriform aperture stenosis (CNPAS) is a rare condition that causes airway obstruction in newborn children, which was first described in 1989 (1). It is caused by an overgrowth of the nasal process of the maxillar, reducing the anterior part of the nasal cavity. It can be diagnosed by physical examination and computed tomography scan. Surgical intervention early in life is usually needed (2-4). CNPAS must be distinguished to choanal atresia, which causes a reduction of the posterior part of the nasal cavity $(1,3)$.

There is limited clinical data concerning this syndrome and the disorder is considered as a mild form of holoprosencephaly (5-9). In patients with CNPAS, familial history of

Received January 23, 2006; accepted May 30, 2006.

Correspondence: Juliane Léger, M.D., Pediatric Endocrinology and Diabetes Unit, Hopital Robert Debré, 48 Bd Sérurier, 75019 Paris, France; Email: juliane.leger@ rdb.aphop-paris.fr

DOI: 10.1203/01.pdr.0000238380.03683.cb holoprosencephaly, cleft palate and ocular coloboma and/or consanguinity have occasionally been reported. An autosomal recessive inheritance of the disorder has been suspected $(3,8,10,11)$. CNPAS occurs as an isolated condition or in association with other midline defects (3-7,9-14). Solitary median maxillary central incisor (SMMCI) (3-6,12-14) and/or pituitary deficiencies $(3,7,10,12,15)$ have been reported. The clinical symptoms of pituitary dysfunction are not always obvious in early childhood and can be potentially severe. Without early diagnosis and appropriate hormonal treatment, morbidity and mortality is high $(3,10,11,16)$. Therefore, the study of additional congenital abnormalities is important for the management and prognosis of the patients. A systematic analysis of the whole phenotypic spectrum associated with CNPAS has not been carried out in previous studies. Therefore, we aimed to investigate the occurrence of pituitary abnormalities and additional malformations in patients with CNPAS and to predict those patients at risk of pituitary dysfunction.

\section{SUBJECTS AND METHODS}

The study population comprised 40 prepubertal children ( 23 girls, 17 boys) with CNPAS. They had a mean age of $3 \pm 3.3$ y $(0.1-10.9 \mathrm{yrs})$ at the time of evaluation. All had been consecutively managed neonatally in the ORL department at the Robert Debré hospital from 1991-2004.

The subjects were examined by a pediatric endocrinologist, geneticist, ophthalmologist and stomatologist. Pituitary function was completely evaluated and magnetic resonance imaging (MRI) of the brain was carried out. Heart, renal, vertebral, dental and chromosomal abnormalities were sought through ultrasonography, radiography and karyotype respectively. Familial history of malformations and/or consanguinity was also recorded.

Growth hormone deficiency (GHD) was diagnosed by auxological data and/or symptoms of endocrine dysfunction (hypoglycemia and/or micropenis), low IGF1 level $(<50 \mathrm{ng} / \mathrm{ml})$ and a growth hormone (GH) peak of less than $10 \mathrm{ng} / \mathrm{ml}$ after provocative testing. Thyroid stimulating hormone (TSH) deficiency was diagnosed by a plasma-free thyroxine (T4) level below 10 $\mathrm{pmol} / \mathrm{L}$ and/or abnormal TSH stimulation after administration of TSH releasing hormone (TRH) (normal values for TSH were, respectively, 0.5-6 mU/L

Abbreviations: CNPAS, congenital nasal pyriform aperture stenosis; CPHD, combined pituitary hormone deficiency; GHD, growth hormone deficiency; HP, hypothalamo-pituitary; PPHS, posterior pituitary hyperintense signal; SMMCI, solitary median maxillary central incisor 
for basal, $14 \pm 7 \mathrm{mU} / \mathrm{L}$ for peak and $<8 \mathrm{mU} / \mathrm{L}$ for $120 \mathrm{~min}$ post-TRH administration). Hyperprolactinemia was defined as basal plasma prolactin levels above $25 \mathrm{ng} / \mathrm{mL}$ in children older than $3 \mathrm{mo}$. Adrenocorticotropic hormone (ACTH) deficiency was diagnosed by morning basal plasma cortisol values below $180 \mathrm{nmol} / \mathrm{L}$ and/or below $450 \mathrm{nmol} / \mathrm{L}$ during insulin-induced hypoglycemia. Gonadotropin function was not evaluated because all the subjects were prepubertal. Diabetes insipidus was excluded by a 12 -h water deprivation test. Combined pituitary hormone deficiency (CPHD) was defined as GHD associated with abnormality of at least one other anterior pituitary hormone. Height was expressed as the SD score (SDS) for sex and chronological age (17).

All MRI images (1.5 Tesla Magnet Philips Intera, Philips Medical Systems, The Netherlands) were reviewed by the same investigator (CG) who was not aware of the endocrinological data. Sagittal and coronal thin $(1.5 \mathrm{~mm})$ slices of the pituitary area were acquired using a gradient echo T1-weighted sequence and coronal slices of the brain were acquired using $\mathrm{T} 2$-weighted sequence. If pituitary stalk was not visible gadolinium injection was used. The height and aspect of the anterior pituitary were recorded and judged to be either normal, hypoplastic $(<-2 \mathrm{SD}$ for age) according to normative data for children $(18,19)$ or absent (not seen). The presence or absence of the pituitary stalk and the location of the posterior pituitary hyperintense signal (PPHS) were recorded. Associated brain abnormalities were also described.

All investigations since the year 2000 were part of a routine clinical management during the neonatal period. Patients born between 1991 and 1999 were evaluated during either the neonatal period $(n=6)$ or after $(n=15)$. Ethic committee approval was not required for this review study, according to French law. Informed consent for the evaluation was obtained from the parents at the time they were performed.

Statistical analysis. Results are expressed as the mean \pm SD. The MannWhitney $U$-test was used for comparison between groups. The percentages within group were compared by the $\chi^{2}$ test.

\section{RESULTS}

HP axis abnormalities. The 40 subjects with CNPAS (Fig. 1) were divided into two groups according to the presence (group $1, n=16,40 \%$ ) or the absence (group 2, $n=24,60 \%$ ) of hypothalamo-pituitary (HP) axis abnormalities. As expected, group 1 subjects were significantly smaller than group 2 subjects (height at $-1.4 \pm 1.4$ versus $0.3 \pm 1.5$ SDS, respectively; $p=0.003$ ).

Group 1 patients were classified into two subgroups: group 1a, as having HP axis abnormalities with anterior pituitary insufficiency $(n=9,22 \%)$ with or without visible anatomical abnormalitiy of HP area on MRI findings; and group $1 \mathrm{~b}$, as having morphologic abnormality of the HP area with normal pituitary function $(n=7,17 \%)$ (Table 1). Group 1a patients showed either CPHD $(n=6)$ or isolated $\operatorname{GHD}(n=3)$. All but one of these patients (patient 9) were diagnosed during the first weeks of life and showed HP axis abnormalities by MRI. Among these patients, eight had symptoms of endocrine dysfunction (hypoglycemia $n=5$, micropenis and cryptorchidism
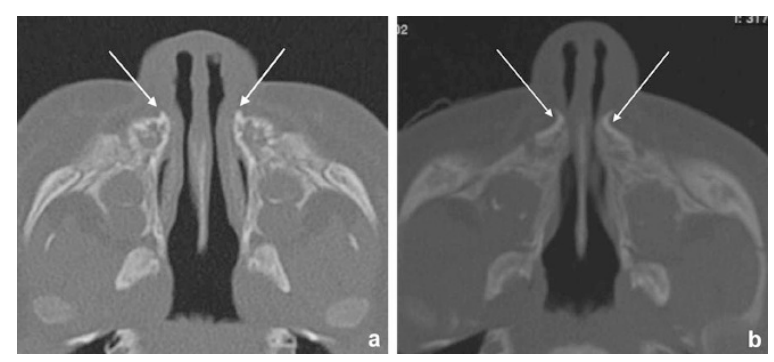

Figure 1. Axial Computed Tomography slice at the level of the maxillary bone $(A)$ Normal pattern with a wide bilateral nasal pyriform aperture (arrows). (B) Congenital nasal pyriform aperture stenosis (arrows). $n=1$, decreased growth velocity $n=3$ ). None of the structure of the HP area was visible in two children, and ectopic PPHS was found in six children (at the median eminence $n=5$, and with a double ectopic PPHS in the proximal and distal levels of the stalk $n=1$ ) (Fig. 2). Interestingly, among subjects without pituitary insufficiency, seven patients had positive MRI for HP area (group 1b patients): Five patients had ectopic PPHS, either located at the distal end of the stalk $(n=2)$ or located along the stalk toward the distal end, communicating with an intrasellar location on the upper side of the anterior pituitary $(n=3)$ (Fig. 2C). Two patients had a hypoplastic anterior pituitary (height $=3.2 \mathrm{~mm}$ at $7 \mathrm{y}$ of age and $2.5 \mathrm{~mm}$ during the neonatal period, respectively).

Other additional congenital malformations. The additional congenital malformations in patients with CNPAS according to the presence or absence of HP axis abnormalities are reported in Table 2. Overall, 31 (78\%) of the 40 patients displayed other additional abnormalities, being all group 1 patients $(n=16)$ and 15 out of the $24(62 \%)$ group 2 patients $(p=0.005)$. The malformations affected the craniofacial area $(n=26)$ : shallow sella turcica, craniopharyngeal canal, solitary median maxillary central incisor (Fig. 3), microcoria, cataract, ptosis; the brain $(n=12)$ : optic nerve hypoplasia, Arnold Chiari malformation, olfactory bulbs agenesis, nystagmus, strabismus, coloboma, micophthalmia; the vertebrae $(n$ $=5)$ : intervertebral synostosis; the limbs $(n=4)$ : hexadactyly, radial hypoplasia; the heart $(n=7)$ : infundibular pulmonary stenosis, interventricular or interauricular septal defect, atrio-ventricular communication, tetralogy of Fallot; or the kidney $(n=3)$ : renal dysplasia, sigmoid kidney, duplication of the pelvis and calices. Patients with HP axis abnormalities had a higher frequency of craniofacial and brain malformations $(n=16,100 \%)$ than patients with a normal HP axis $(n$ $=13,54 \%) ; p=0.002$. A SMMCI was the most frequently observed malformation ( $n=22,55 \%$ of cases) and was found significantly more often in children with HP axis abnormalities than in children with a normal HP axis $(81 \%$ versus $37 \%$; $p=0.006$ ).

In the studied population, we identified three known associations in six patients (15\% of cases): four cases of VACTERL syndrome (vertebral defects, anal atresia, cardiac defects, tracheo-esophageal fistula, renal anomaly, limb defect); one case of CHARGE syndrome (Coloboma, heart defect, atresia of the choanae, retardation of growth and development, genital anomalies), and one case of RHYNS syndrome (retinis pigmentosa, hypopituitarism, nephronophtisis, mild skeletal dyplasia). There was no difference in the proportion of these anomalies between group 1 and group 2 patients. Moreover, only two of the patients had chromosomal anomalies $(46 \mathrm{XX}, \operatorname{del}(\mathrm{X})(\mathrm{p} 11)$ and 22q11 deletion, respectively).

Familial history. A familial component was suspected in 12 patients (30\% of cases), with a similar proportion between group 1 and group 2 patients. Parental consanguinity $(n=9)$ and/or familial history of midline malformation $(n=5)$ and/or anterior pituitary deficiency $(n=1)$ were found (table 2$)$. 
GUILMIN-CRÉPON ET AL.

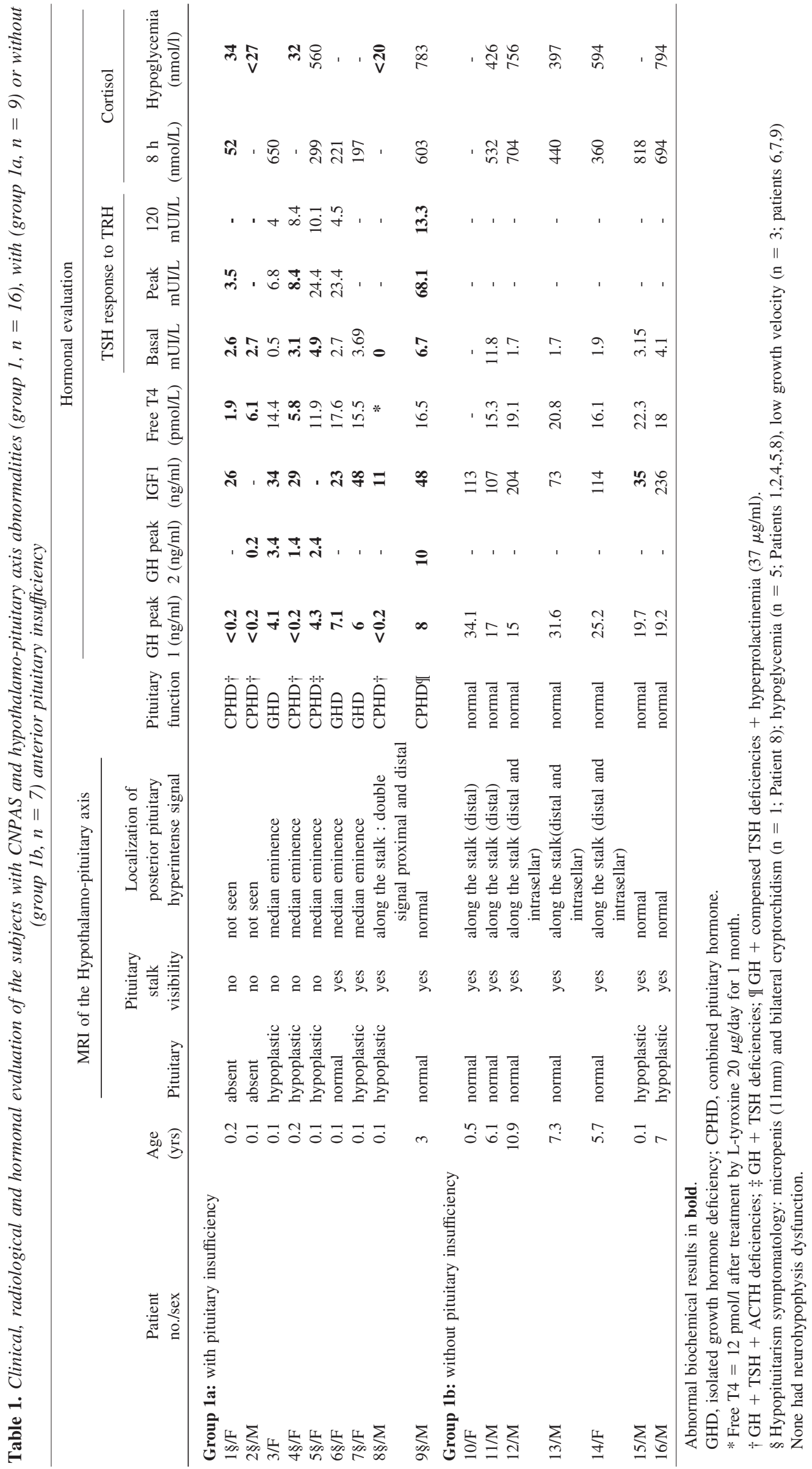



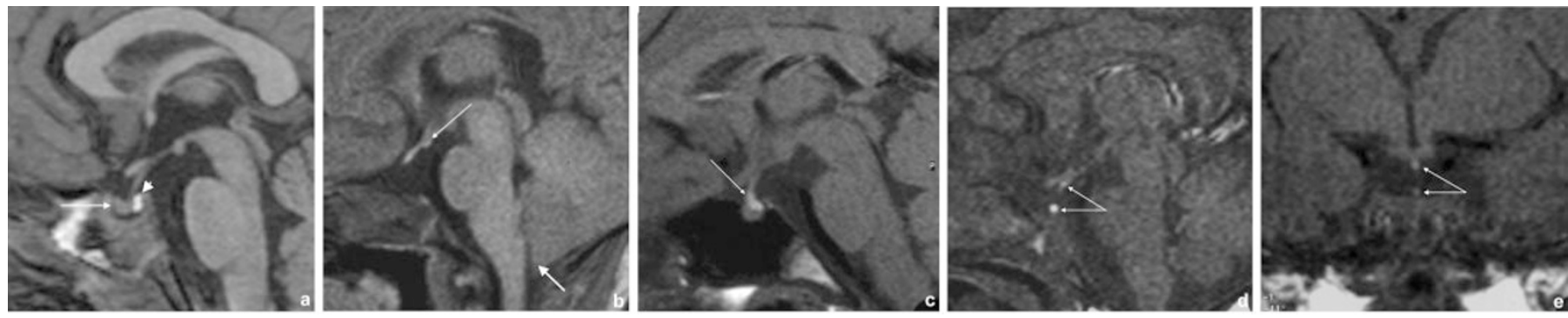

Figure 2. Variable location of the ectopic neurohypophysis on MRI. (A) Normal appearance of pituitary gland in a 7-y-old child. Anterior pituitary gland (arrow) Hyperintense posterior pituitary gland (arrowhead) (B) Patient 4, T1 weighted sagittal slice. Hypoplastic anterior pituitary, no pituitary stalk being visible (even after gadolinium injection). The hyperintensity of the ectopic pituitary is at the median eminence (arrow). Associated abnormalities were shallow sella turcica and Arnold Chiari malformation (large arrow). (C) Patient 12, T1 weighted sagittal slice. The hyperintensity of the ectopic neurohypophysis is visible in the distal portion of the pituitary stalk and communicates with an intrasellar neurohypophysis (arrow). The anterior pituitary and the pituitary stalk have a normal appearance. $(D, E)$ Patient $8, \mathrm{~T} 1$ weighted sagittal and coronal slices. Double ectopic hypersignal of the neurohypophysis in the distal and the proximal portions of the pituitary stalk.

\section{DISCUSSION}

In this study, we found important associations between CNPAS, midline craniofacial and brain lesions, pituitary abnormalities and other additional congenital defects. Only nine patients (22\% of cases) showed isolated CNPAS with no other congenital malformations or HP axis abnormality. Previous studies on reported associated malformations in CNPAS were conducted in the form of case reports or small series and none of them have systematically screened patients for pituitary insufficiency and/or associated malformations. The present study conducted on a cohort of clinically well characterized patients with CNPAS demonstrated that CNPAS rarely appears isolated and expand the spectrum of phenotype in these patients.

SMMCI and HP axis abnormalities were the most common associated disorders, which were found in $55 \%$ and $40 \%$ of cases, respectively. For patients with HP axis abnormalities, we found endocrine dysfunction in $56 \%$ of the cases. A normal HP axis on MRI was highly predictive of normal endocrine function. Only one of our patients with a normal HP axis on MRI showed an endocrinopathy. Ectopic neurohypophysis was the most frequent HP axis abnormality. This finding is consistent with several reports demonstrating that ectopic neurohypophysis is commonly associated with midline craniofacial and/or brain malformation (20-24). Ectopic neurohypophysis was located either at the median eminence or at different areas along the pituitary stalk. Surprisingly, one patient showed a double ectopic PPHS, at both the proximal and distal areas of the pituitary stalk. Three patients with normal endocrine function demonstrated a variant of ectopic PPHS, with the hyperintense signal of the neurohypophysis being visible in the distal portion of the pituitary stalk that communicates with an intrasellar neurohypophysis. Location of ectopic PPHS along the stalk has been shown to predict a less severe form of the disease $(25,26)$. To our knowledge, these aspects in the location of the posterior pituitary hyperintense signal have not been previously described. It remains to be seen whether group $1 \mathrm{~b}$ patients will develop endocrine dysfunction later in life.

All patients with CNPAS and HP axis abnormalities showed at least one other craniofacial or brain anomaly. The most frequent was SMMCI, which occurred in all but one group 1 patient. Although previously less frequently observed, craniofacial and brain findings are primarily consistent with those of previous reports $(3,4,12)$. The relatively high incidence of olfactory bulbs agenesis in the present study was also found to occur most frequently in patients with HP axis abnormalities. As SMMCI, CNPAS has long been reported as a mild form of holoprosencephaly (5-9). The association of holoprosencephaly with a wide variety of craniofacial and extracranial anomalies is well recognized and individuals with holoprosencephaly have been ascribed to a variety of syndromes with multiple congenital anomaly $(27,28)$. Our study showed that extracranial anomalies also frequently occurred in patients with CNPAS. These findings have not been addressed in previous studies apart in four cases with VACTERL syndrome (29), with a ring chromosome 18 (6) and with multiple congenital malformations including cardiovascular, gastrointestinal and limbs anomalies (7), respectively. Although choanal atresia is a clinical feature of CHARGE syndrome (30), CHARGE and RHYNS syndromes have not been previously reported as associated with CNPAS.

The pathogenesis of CNPAS is still unknown. As in our study, features of holoprosencephaly ranging from severe to mild forms such as SMMCI or cleft palate, have been identified by studying first-degree relatives of patients with CNPAS and consanguinity has also been described through familial study $(3,8,10,11)$. This suggests that genetic and/or environmental factors may play a role in the pathogenesis of the disease. A mutation in the sonic hedgehog ( $\mathrm{SHH}$ ) gene has been reported in one case with CNPAS and semilobar holoprosencephaly. This mutation was inherited from the father who had hypotelorism only (31). A mutation in the SHH gene has also been associated in one sporadic case with midnasal stenosis and SMMCI (31). A number of genes for holoprosencephaly have been identified. These were mostly SHH, TGIF, ZIC2 and SIX3 genes. Abnormalities in these genes have mostly been found in familial cases of holoprosencephaly spectrum (31). Half of the mutations have been found in the SHH gene, which is known to play a critical role in early forebrain and CNS development. However, as no anomaly to these genes were found in $80 \%$ of holoprosencephaly cases, other genes are likely to be involved $(27,31)$. As reported in 


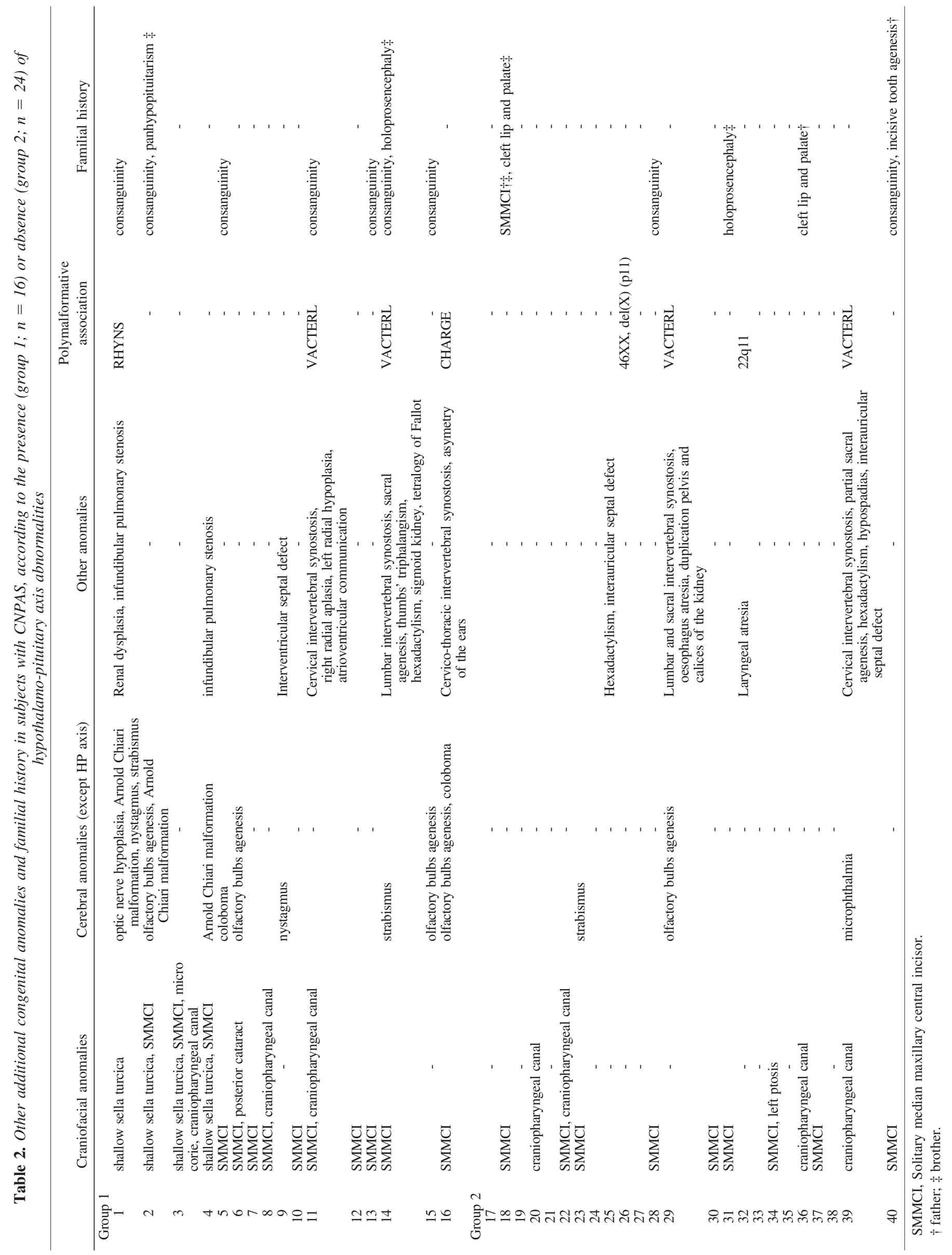



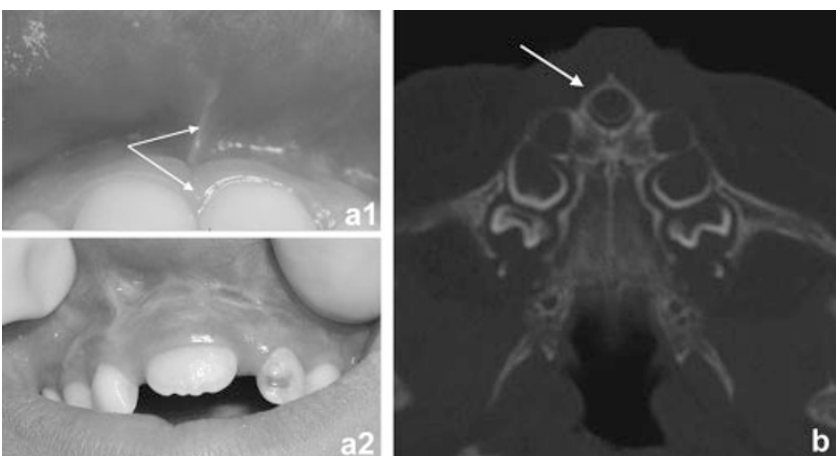

Figure 3. Solitary Median Maxillary Central Incisor (SMMCI) diagnosed by clinical and radiologic evaluation. (a1) Normal central dentition: note the frenulum labii superiosis and the intermaxillary suture (arrows) (a2) SMMCI, absence of the frenulum labii superioris and of the intermaxillary suture. (b) Axial Computed Tomography slice at the level of the maxillary bone demonstrating a SMMCI (arrow).

patients with features of holoprosencephaly spectrum $(27,31)$, CNPAS may be a genetically heterogeneous condition with transmission occurring along various pattern (recessive or dominant mode of inheritance) and with a large phenotypic variability that shares common etiological mechanisms with the various form of holoprosencephaly phenotype. Mechanism by which the variable expressivity of the disorder may occur could be due to multigenic (32) or environmental influences (33) or as demonstrated for the SHH gene, may be due to a temporal disruption of a single molecular pathway during embryonic development (34). Recently, animal models have shown that a coordinated interaction between epithelial and mesenchymal cells is essential during the initial stages of palate development (35). Moreover, although half of all patients with CHARGE syndrome have CHD7 gene abnormalities (36), disruption to the epithelial-mesenchymal interaction has also been proposed to explain the pathogenesis of this affection, which includes multiple congenital anomalies involving different organs and tissues $(37,38)$. These theories can explain the features of holoprosencephaly spectrum and as in our patients, the association of multiple congenital anomalies. The six hormone-producing cell types of the pituitary differentiate from a common population of ectodermal progenitors through the sequentially action of several transcription factors during pituitary development (39). However, it remains unclear how the developmental signaling systems interact during embryogenesis of the face, forebrain and pituitary.

In conclusion, CNPAS covers many features of the holoprosencephaly spectrum associated with craniofacial and extracranial anomalies. Long-term morbidity is related to the additional malformations. These patients should be carefully assessed during the neonatal period and a cerebral MRI is required before surgery. Patients with an abnormal HP axis are at a greater risk of endocrine dysfunction than those with a normal HP axis. These patients require prompt diagnosis and hormone replacement therapy to prevent a potentially life threatening and/or developmental delay due to hypoglycaemia, hypocortisolism and hypothyroidism and to ensure normal growth. Therefore, complete biochemical endocrine testing is justified during the neonatal period when an abnormal
HP axis is seen by cerebral MRI, because ectopic PPHS or aplasia of the anterior pituitary are reliable indicators of endocrine dysfunction,. For other cases, the clinical features of pituitary deficiency should be detected during infancy to determine promptly those patients requiring a blood sample for determining plasma free T4, TSH, cortisol and IGF1 levels. Repeated investigations should be required for those patients who have abnormal HP axis on MRI but test normal initially or for those patients who develop clinical signs of endocrine dysfunction (i.e., growth retardation) later in life. Careful assessment for other midline defects or physical findings should be done. Apart from SMMCI and HP axis abnormalities, most of the associated malformations are variable. They share considerable phenotypic overlap beyond craniofacial, heart, renal and limb anomalies. Therefore, counseling patients with CNPAS and their families is difficult for clinicians.

\section{REFERENCES}

1. Brown OE, Myer CM, Manning SC 1989 Congenital nasal pyriform aperture stenosis. Laryngoscope 99:86-91

2. Leiberman A, Carmi R, Bar-Ziv Y, Karplus M 1992 Congenital nasal stenosis in newborn infants. J Pediatr 120:124-127

3. Van Den Abbeele T, Triglia JM, François M, Narcy P 2001 Congenital nasal pyriform aperture stenosis: diagnosis and management of 20 cases. Ann Otol Rhino Laryngol 110:70-75

4. Losken A, Burstein FD, Williams JK 2002 Congenital nasal pyriform aperture stenosis: diagnosis and treatment. Plast Reconstr Surg 109:1506-1511

5. Arlis H, Ward RF 1992 Congenital nasal pyriform aperture stenosis. Isolated abnormality vs developmental field defect. Arch Otolaryngol Head Neck Surg 118:989-991

6. Tavin E, Stecker E, Marion R 1994 Nasal pyriform aperture stenosis and the holoprosencephaly spectrum. Int J Pediatr Otorhinolaryngol 28:199-204

7. Hui Y, Friedberg J, Crysdale WS 1995 Congenital nasal pyriform aperture stenosis as a presenting feature of holoprosencephaly. Int J Pediatr Otorhinolaryngol 31:263274

8. Krol BJ, Hulka GF, Drake A 1998 Congenital nasal pyriform aperture stenosis in the monozygoyic twin of a child with holoprosencephaly. Otolaryngol Head Neck Surg 118:679-681

9. Chan EY, Ng DK, Chong AS, Hui Y, Fu YM 2005 Congenital nasal pyriform aperture stenosis with semilobar holoprosencephaly. Int J Pediatr Otorhinolaryngol 69:93-96

10. Beregszaszi M, Léger J, Garel C, Simon D, François M, Hassan M, Czernichow P 1996 Nasal pyriform aperture stenosis and absence of the anterior pituitary gland: report of two cases. J Pediatr 128:858-861

11. Bignault A, Castillo M 1994 Congenital nasal piriform aperture stenosis. AJNR Am J Neuroradiol 15:877-878

12. Lo FS, Lee KS, Lin SP, Shen LS, Huang JK, Lee KS 1998 Solitary maxillary central incisor and congenital nasal pyriform aperture stenosis. Eur J Pediatr 157:39-44

13. Royal SA, Hedlund GL, Wiatrak BJ 1999 Single central maxillary incisor with nasal pyriform aperture stenosis-CT diagnosis prior to tooth eruption. Pediatr Radiol 29:357-359

14. Huang JK, Cheng SJ, Yang CC, Yun CH, Shih SL 2004 Congenital nasal pyriform aperture stenosis and single central maxillary incisor: preoperative evaluation with three dimensional computed tomography. J Formos Med Assoc 103:37-40

15. Godil MA, Galvin-Parton P, Monte D, Zerah M, Purandare A, Lane AH, Wilson TA 2000 Congenital nasal pyriform aperture stenosis associated with central diabetes insipidus. J Pediatr 137:260-262

16. Cameron FJ, Khadilkar W, Stanhope R 1999 Pituitary dysfunction, morbidity and mortality with congenital midline malformation of the cerebrum. Eur J Pediatr 158:97-102

17. Sempé M, Pedron G, Roy-Pernot MP 1970 Auxologie, methodes et sequences. Theraplix, Paris

18. Argyropoulou M, Perignon F, Brunelle F, Brauner R, Rappaport R 1991 Height of normal pituitary gland as a function of age evaluated by magnetic resonance imaging in children. Pediatr Radiol 21:247-249

19. Fink AM, Vidmar S, Kumbla S, Pedreira CC, Kanumakala S, Williams C, Cralin JB, Cameron FJ 2005 Age-related pituitary volumes in prepubertal children with normal endocrine function: volumetric magnetic resonance data. J Clin Endocrinol Metab 90:3274-3278

20. Brodsky MC, Glasier CM 1993 Optic nerve hypoplasia. Clinical significance of associated central nervous system abnormalities on magnetic resonance imaging. Arch Ophthalmol 111:66-74

21. Phillips PH, Spear C, Brodsky MC 2001 Magnetic resonance diagnosis of congenital hypopituitarism in children with optic nerve hypoplasia. J AAPOS 5:275-280 
22. Traggiai C, Stanhope R 2002 Endocrinopathies associated with midline cerebral and cranial malformations. J Pediatr 140:252-255

23. Birkebaek NH, Patel L, Wright NB, Grigg JR, Sinha S, Hall CM, Price DA, Lloyd IC, Clayton PE 2003 Endocrine status in patients with optic nerve hypoplasia: relationship to midline central nervous system abnormalities and appearance of the hypothalamic-pituitary axis on magnetic resonance imaging. J Clin Endocrinol Metab 88:5281-5286

24. Simon D, Hadjiathanasiou CG, Garel C, Czernichow P, Léger J 2006 Phenotypic variability in children with growth hormone deficiency associated with posterior pituitary ectopia. Clin Endocrinol (Oxf) 64:416-422

25. Chen S, Léger J, Garel C, Hassan M, Czernichow P 1999 Growth hormone deficiency with ectopic neurohypophysis: anatomical variations and relationship between the visibility of the pituitary stalk asserted by magnetic resonance imaging and anterior pituitary function. J Clin Endocrinol Metab 84:2408-2413

26. Léger J, Danner S, Simon D, Garel C, Czernichow P 2005 Do all patients with childhood onset growth hormone deficiency and ectopic neurohypophysis have persistent GHD in adulthood. J Clin Endocrinol Metab 90:650-656

27. Lazaro L, Dubourg C, Pasquier L, Le Duff F, Blayau M, Durou MR, Thomas de la Pintière A, Aguilella C, David V, Odent S 2004 Phenotypic and molecular variability of the holoprosencephalic spectrum. Am J Med Genet A 129:21-24

28. Siebert JR, Schoenecker KA, Resta RG, Kapur RP 2005 Holoprosencephaly and limb reduction defects: a consideration of Steinfeld Syndrome and related conditions. Am J Med Genet A 134:381-392

29. Captier G, Tourbach S, Bigorre M, Saguintaah M, El Ahmar J, Montoya P 2004 Anatomical consideration of the congenital nasal pyriform aperture stenosis: localized dysostosis without interorbital hypoplasia. J Craniofac Surg 15:490-496

30. Hall BD 1979 Choanal atresia and associated multiple anomalies. J Pediatr 95:395-
31. Dubourg C, Lazaro L, Pasquier L, Bendavid C, Blayau M, Le Duff F, Durou MR, Odent S, David V 2004 Molecular screening of SHH, ZIC2, SIX3 and TGIF genes in patients with features of holoprosencephaly spectrum: mutation review and genotype-phenotype correlations. Hum Mutat 24:43-51

32. Ming JE, Muenke M 2002 Multiple hits during early embryonic development: digenic diseases and holoprosencephaly. Am J Hum Genet 71:1017-1032

33. Finnell RH, Waes JG, Eudy JD, Rosenquist TH 2002 Molecular basis of environmentally induced birth defects. Annu Rev Pharmacol Toxicol 42:181-208

34. Cordero D, Marcucio R, Hu D, Gaffield W, Tapadia M, Helms JA 2004 Temporal perturbations in sonic hedgehog signalling elicit the spectrum of holoprosencephaly phenotypes. J Clin Invest 114:485-494

35. Rice R, Spencer-Dene B, Connor EC, Gritli-Linde A, McMahon AP, Dickson C, Thesleff I, Rice DP 2004 Disruption of Fgf10/Fgfr2b-coordinated epithelialmesenchymal interactions causes cleft palate. J Clin Invest 113:1692-1700

36. Vissers LE, Van Ravenswaaij CM, Admiraal R, Hurst JA, de Vries BB, Janssen IM, Van der Vliet WA, Huys EH, de Jong PJ, Hamel BC, Schoenmakers EF, Brunner HG, Veltman JA, Van Kessel AG 2004 Mutations in a new member of the chromodomain gene family cause CHARGE syndrome. Nat Genet 36:955957

37. Williams MS 2005 Speculations on the pathogenesis of CHARGE Syndrome. Am J Med Genet 133A:318-325

38. Pinto G, Abadie V, Mesnage R, Blustajn J, Cabrol S, Amiel J, Hertz-Pannier L, Bertrand AM, Lyonnet S, Rappaport R, Netchine I 2005 CHARGE syndrome includes hypogonadotropic hypogonadism and abnormal olfactory bulb development. J Clin Endocrinol Metab 90:5621-5626

39. Olson LE, Rosenfeld MG 2002 Genetic and genomic approaches in elucidating mechanisms of pituitary development. Endocrinology 143:2007-2011 